\title{
Responsibility of Family Doctors in Health Services for BPJS Health Participants in Mataram City
}

\author{
Mualifah \\ Faculty of Law, Institute for Research, and Community Service \\ University of Mataram \\ Mataram, Indonesia \\ mualifah@unram.ac.id
}

\begin{abstract}
Health services are provided through the form of medication and care. Health workers, medical and nonmedical, are responsible for providing optimal service. Medical personnel, in terms of doctors, have the responsibility for the treatment that is being carried out. Treatment actions and determining needs in the treatment process are under the authority of the doctor. In accordance with the formulation of the problem and the research objectives, this legal research uses a normative or dogmatic approach to law as its main approach, with the aim of studying its positive law in the sense of collecting, presenting, systematizing, analyzing, interpreting and assessing positive legal norms that protect the rights of the community. Health BPJS. The purpose of this legal research is to find the form of health services for BPJS Kesehatan participants by family doctors. Family doctor is a doctor who collaborates with BPJS Kesehatan, who is responsible for the health services provided to BPJS Kesehatan participants without differentiating between classes / categories of membership for BPJS Kesehatan patients. This family doctor receives a reward provided by BPJS Kesehatan in accordance with the services provided by the doctor for BPJS Kesehatan participant patients.
\end{abstract}

\section{Keywords—Health Services, BPJS, Family Doctors}

\section{INTRODUCTION}

The development of the health sector is basically shown to increase awareness, willingness and ability to live a healthy life for everyone. In order to achieve an optimal degree of health as one of the elements of welfare, as mandated by the opening of the 1945 Constitution of the Republic of Indonesia, doctors and dentists and other paramedics as the main components of providing health services to the community, have an important role [1]. This is directly related to the provision of health services and the quality of services provided.

The main foundation for doctors and dentists, as well as other paramedics in carrying out medical treatment against other people, is the knowledge, technology and competencies that are acquired through education and training [2]. The knowledge they have must be continuously maintained and improved in accordance with the progress of science and technology itself. Paramedics with their scientific instruments have distinctive characteristics. This can be seen from the justification given by law, namely being allowed to take medical action against the human body in an effort to maintain and improve the health status. Medical action against the human body that is not carried out by a doctor or dentist can be classified as a criminal offense.
The lack of public trust in doctors and dentists and other paramedics and the increasing number of lawsuits filed by the public today is often identified with the failure of healing efforts carried out by paramedics [3]. Conversely, if the medical action carried out can be considered excessive, then the paramedics, with the tools of science and technology at their disposal, only try to heal. Failure to apply medical science is not always synonymous with failure in action.

In health care, conflicts can occur between peers of health workers, health workers and patients, or with partner institutions. It cannot be denied that cultural changes and developments have changed the pattern of human life so that it leads to individualistic, arrogant and selfish traits. This weakens the spirit of togetherness and the mutual cooperation of life with this new character, which triggers the possibility of conflict or dispute. Conflict is an emotional reaction to a situation or interaction that shows a mismatch or mismatch.

Health services are provided through the form of medication and care. Health workers, medical and nonmedical, are responsible for providing optimal service. Medical personnel, in this case doctors, have responsibility for the treatment that is being carried out. Treatment actions and determining needs in the treatment process are the authority of the doctor. The norms regarding the existence of health are still relatively new. In its development in Indonesia, it was originally developed by Fred Ameln and the late Prof. Oetama in the form of medical law. The rapid development of life in the health sector in the form of a national health system results in the need for a broader regulation, from medical law to matters relating to health (health law) [4].

Health law in Indonesia today cannot be separated from the legal system adopted by a country and / or society, so there are 2 (two) legal systems in the world, which are codified civil law systems and common law systems. Then it is possible that there is a mixed legal system, especially for a pluralistic society like Indonesia which allows to adopt a mixed legal system. In this regard, in order to provide legal certainty and protection, both for health service providers and for health service recipients, to improve, direct and provide a basis for development in the health sector, a dynamic health legal instrument is required. There have been many changes to health principles, especially regarding the rights and obligations of the parties involved in health efforts as well as legal protection for the parties concerned. 


\section{METHODS}

This research is a literature review research [5]. The literature reviewed is related to the responsibilities of family doctors in health services for BPJS participants. The population taken was all family doctors in Mataram city. The study was conducted regarding the rights and obligations of BPJS health participants, the benefits of the BPJS for health, the form of services from the BPJS for health and related to family doctors, their rights and obligations.

\section{RESULTS AND DISCUSSION}

\section{A. Rights and Obligations of BPJS Kesehatan participants}

Participants' Rights: Obtain participant cards as participant identities to obtain health services, Obtain benefits and information about rights and obligations as well as health service procedures in accordance with applicable regulations [6], Obtain health services at health facilities in collaboration with BPJS Kesehatan and, submit complaints / complaints, criticisms and oral or written advice to BPJS Kesehatan,

Obligations of Participants: Register themselves and their family members as BPJS Health participants, pay dues, provide complete and correct data about themselves and their family members, report changes in their personal data and family members, including changes in class, rank or salary, marriage, divorce, death , birth, change of address, and move to first level health facilities. Obey all the provisions and procedures for health services. Benefits of BPJS Health Services: Every participant has the right to receive health insurance benefits that are individual health services, including promotional, preventive, curative and rehabilitative services including services for medicines and consumable medical materials according to the medical needs required [7].

The benefits of promotive and preventive services include the provision of (a) Individual health counseling, which includes at least counseling on the management of disease risk factors and clean and healthy living habits, (b) Basic immunization, including Baccile Calmett Guerin (BCG), Tetanus Diphtheria and Hepatitis B (DPT-HB), Polio and Measles, (c) Guaranteed family planning services include counseling, basic contraception, facectomy, and tubectomy in collaboration with institutions in charge of family planning, (d) Health screening is given selectively aimed at detect the risk of disease and prevent the aftereffects and risks of certain diseases. Provisions regarding the procedure for providing health screening services for types of disease, and health screening service time as referred to are stipulated in the regulation of the minister of health.

Health insurance benefits as referred to consist of medical benefits and non-medical benefits. Medical benefits are not tied to the amount of contributions paid [8]. Non-medical benefits include accommodation and ambulance benefits. Accommodation benefits are differentiated based on the scale of the contributions paid. Ambulance is only given to referral patients from health facilities with certain conditions as determined by BPJS.

\section{Forms of BPJS Health Services}

Health services guaranteed by BPJS Kesehatan include:

1. First Level Health Services: service administration, preventive promotive services, examination, treatment, and medical consultation, non-specialized medical actions, both operative and non-operative, services for drugs and consumable medical materials, first-level laboratory diagnostic support examinations, examinations for pregnant women, childbirth, breastfeeding mothers and babies, efforts to cure side effects of contraception, including handling complications of postpartum family planning; basic medical rehabilitation.

2. Advanced level referral health services, including outpatient and inpatient health services, which include: service administration, examination, treatment and specialist consultation by specialists and sub-specialists, specialist medical actions according to medical indications, drug services and consumable medical materials, medical device services, advanced diagnostic support services in accordance with medical indications; medical rehabilitation, blood services, clinical forensic medical services, corpse services are limited to participants who die after being hospitalized at a health facility in collaboration with BPJS where the patient is treated in the form of corpses and does not include coffins

3. Births. Births that are covered by BPJS Kesehatan in health facilities at the first level and at the advanced level are deliveries up to a third child, regardless of whether the child is alive / dead.

4. Ambulance. Ambulance is only given for referral patients from one health facility to another, with the aim of saving the patient's life.

Family doctors are general practitioners who work with BPJS Kesehatan according to article 50 of Law no. 29 of 2004 concerning medical practice determines that doctors have the following rights: (a) Obtaining legal protection as long as they carry out their duties according to professional standards and standard operational procedures, (b) Providing medical services according to professional standards and operational procedure standards. (c) Obtain complete and honest information from patients or their families and (d) Receive fees for services.

According to Article 51 of the same law in carrying out medical practice, doctors have the obligation to: (a) Provide medical services in accordance with professional standards and standard operational procedures and patient medical needs, (b) Refer patients to other doctors who have expertise or better, if unable to carry out an examination or treatment, (c) Keep everything that knows about the patient a secret, even after the patient has died, (d) Perform emergency aid on a humanitarian basis, unless he is sure that someone else is on duty and capable do so, and (e) Increase knowledge and follow the development of medical science.

Patients in receiving services in medical practice in article 52 of the medical practice law have the right to get a complete explanation of medical actions as referred to in article 45 paragraph 3 , ask for the opinion of other doctors, receive 
services in accordance with medical needs, refuse medical action and get medical attention [9]. fill in medical records. According to Article 53 of the Law on medical practice, patients have the obligation to provide complete and honest information about their health problems, comply with doctor's advice and instructions, comply with applicable provisions in health services and provide compensation for services received. Family doctor is a doctor who collaborates with BPJS Kesehatan to provide free health services for BPJS health participants. Free means that patients who participate in BPJS Kesehatan have already paid for it. Provide referrals or further tests such as laboratory tests. Family doctor services include: service administration, examination services, medical treatment and consultation, and non-specialized medical actions.

\section{CONCLUSION}

A family doctor is a general practitioner who works in a hospital or clinic and opens an independent practice in collaboration with BPJS Kesehatan, because a family doctor is a general practitioner, his responsibility is limited to the initial examination or first-level health facilities whose function is like a health center. Those who become family doctors should not only be general practitioners but also specialist doctors so that it can reduce the accumulation of BPJS Kesehatan participant patients who seek treatment at the hospital.

\section{REFERENCES}

[1] T. Rasku, M. Kaunonen, E. Thyer, E. Paavilainen, and K. Joronen, "The core components of community paramedicine-integrated care in primary care setting: a scoping review," Scand. J. Caring Sci., vol. 33, no. 3, pp. 508-521, 2019.

[2] A. Bullock et al., "Transitions in medicine: trainee doctor stress and support mechanisms," J. Work. Learn., 2013.

[3] J. S. Felton, "Burnout as a clinical entity-its importance in health care workers," Occup. Med. (Chic. Ill)., vol. 48, no. 4, pp. 237-250, 1998.

[4] L. O. Gostin and L. F. Wiley, Public health law: power, duty, restraint. Univ of California Press, 2016.

[5] C. Hart, "Doing a literature review: Releasing the research imagination," 2018.

[6] D. Biswas, M. Kristiansen, A. Krasnik, and M. Norredam, "Access to healthcare and alternative health-seeking strategies among undocumented migrants in Denmark," BMC Public Health, vol. 11, no. 1, pp. 1-11, 2011

[7] L. A. Curtis and A. Burns, Unit costs of health and social care 2015. Personal Social Services Research Unit, 2015.

[8] C. Aspalter, K. Jinsoo, and P. Sojeung, "Analysing the Welfare State in Poland, the Czech Republic, Hungary and Slovenia: An idealtypical perspective," Soc. Policy Adm., vol. 43, no. 2, pp. 170-185, 2009.

[9] L. I. Horwitz et al., "Quality of discharge practices and patient understanding at an academic medical center," JAMA Intern. Med., vol. 173, no. 18, pp. 1715-1722, 2013. 